\title{
Effect of Oral Clonidine on Hemodynamic Response During Surgery
}

\author{
Regmi BS*, Regmi SR*, Pradhan B*, Marahatta $\mathrm{MN}^{*}$, Dubey $\mathrm{L}^{*}$ \\ *Shahid Gangalal National Heart Centre, Bansbari, Kathmandu
}

\section{ABSTRACT}

Clonidine is an alpha 2-adrenoceptor agonist. It has recently, however, found a new and possibly significant role in anaesthesia and the treatment of pain. Diazepam has been used as a drug for premedication for years but oral clonidine has not been used as premedication even though it is cheaper and has longer postoperative analgesic effect. This prospective, double blind randomized study was conducted in department of anaesthesiology, institute of medicine, TUTH. A total 60 consecutive patients scheduled for abdominal gynaecological surgeries were randomized to clonidine or diazepam premedication group and received these drug one hour before surgery planned under spinal anaesthesia. Intraoperative haemodynamic changes in terms of blood pressure, heart rate, oxygen saturation, were recorded.

Hypotension was occurred in 9(15\%) in clonidine group and 10(16.7\%) in diazepam group, (p value $>0.05)$. During surgery, bradycardia was noted in $6(10 \%)$ vs. $3(5 \%)$ patient in diazepam and clonidine group respectively ( $\mathrm{p}$ value $>0.05$ ). Nausea, shivering, restlessness were other side effects seen during surgery in both clonidine and diazepam group (33.33\% vs. $36.66 \%)$. Although few more cases of nausea ( 1 vs. 5) with clonidine and few more cases of restless (3 vs. 7) were noted with diazepam, the overall difference was not statistically significant between two groups ( $\mathrm{p}$ value $>0.05$ ). Oral clonidine premedication had similar hemodynamic response to diazepam. It is cheaper and has longer postoperative analgesic effect as well as similar sedative effect.

Key words: Clonidine, intraoperative haemodynamic change, blood pressure

Correspondence:

Dr. Bharati Sharma Regmi, Department of Anaesthesia, SGNHC

Phone: 9841347147 ,

E-mail: bharututh@hotmail.com 


\section{INTRODUCTION}

Clonidine is an alpha 2-adrenoceptor agonist. It was synthesized in 1960s and has been used for over 20 years to treat hypertension. ${ }^{1}$ It has recently, however, found a new and possibly significant role in anaesthesia and the treatment of pain. ${ }^{2}$ Clonidine is a direct-acting alphaadrenergic agonist with a strong preference for the alpha- 2 receptor. It acts centrally to produce inhibition of sympathetic vasomotor centers by inhibiting release of norepinephrine in the medulla. ${ }^{3}$ Sympathetic tone is reduced, thus decreasing systemic blood pressure. ${ }^{4}$ When used for the acute or chronic management of hypertension, the reduction in sympathetic tone decreases systemic vascular resistance, heart rate, and blood pressure. $^{5}$

Clonidine is rapidly and completely absorbed by the oral route, reaching peak plasma level in 60 to 90 minutes. ${ }^{6}$ One of the major side effects of clonidine as an antihypertensive agent is its significant sedative property. ${ }^{7}$ This is thought to be mediated by stimulation of alpha-2 receptors in the locus ceruleus, the area of the brain that modulates wakefulness. ${ }^{8}$ This characteristic limits clonidine's use as an antihypertensive agent but is an attractive quality to the anesthesiologist due to its perioperative sedation. Its sedative effects, combined with anxiolysis and a favorable haemodynamic profile at low doses, makes clonidine a good preoperative medication. In fact, the anxiolytic effects of clonidine and benzodiazepines have been demonstrated to be comparable.9 Clonidine has the further advantage of producing sedation that is associated with only very small reductions in minute ventilation and no effect on hypercapnic or hypoxic respiratory drives. Thus it can be given in a relatively unmonitored environment such as a preoperative holding area. These central effects were also discovered to have advantages intraoperatively. ${ }^{10}$ Clonidine attenuates sympathetically mediated hyperdynamic responses, making it a useful adjunct in patients at risk for myocardial ischemia. It can decrease the stress response to laryngoscopy as well as emergence from anesthesia and reduces perioperative catecholamine release overall. ${ }^{11}$

Diazepam has been used as a drug for premedication for years but clonidine has not been used as premedication even though it is cheaper and has longer postoperative analgesic period. This double blind, randomized study is designed to evaluate postoperative analgesic effect of oral clonidine premedication vs. oral diazepam premedication in spinal anaesthesia with hyperbaric $0.5 \%$ bupivacaine.

This study was aimed to compare the intraoperative haemodynamic changes between oral clonidine and diazepam premedication in spinal anaesthesia with bupivacaine in abdominal gynaecological surgeries.

\section{MATERIALS AND METHODS}

After obtaining approval from institutional ethics committee, this prospective and randomized study was carried out in 60 ASA grade I and II patients scheduled for elective abdominal gynaecological surgeries in the operation theatre of Tribhuvan University Teaching Hospital (TUTH), Institute of Medicine, Maharajgunj, Kathmandu, Nepal since first Baisakh 2065 to first Falgun 2065.

INCLUSION CRITERIA

- Patients of ASA I \& II grading.

- All patients aged between 18-60 years for elective abdominal gynaecological surgeries.

- Patients with controlled hypertension $(\mathrm{BP}<140 / 90 \mathrm{mmHg})$ on antihypertensive drug other than clonidine.

\section{EXCLUSION CRITERIA}

- Patients of ASA physical status more than II and contraindicated for neuraxial block.

- Concomitant intake of clonidine and /or diazepam.

- Patients with acute or chronic liver, renal disease.

All patients were assessed one day before surgery as routine pre-anaesthetic check-up. The procedure, alternative methods and possible complications were explained to the patient in her own language. Informed and written consent was taken. All patients were premedicated with single dose diazepam $0.2 \mathrm{mg} / \mathrm{kg}$ at bed time and advised for nil per orally from midnight the day before surgery. Patient was transferred to operation theatre preparation room on the day of operation. Base line blood pressure, heart rate and oxygen saturation were recorded. IV cannulation was done by $18 \mathrm{G}$ cannula. Patients were divided 
randomly into two groups. Group 1 (clonidine ) and Group 2 (diazepam), each consisting of 32 patients. Randomization was accomplished by using sealed envelope method. Group 1 (clonidine) received $0.004 \mathrm{mg} / \mathrm{kg}$ of oral clonidine and Group 2 (diazepam) received $0.2 \mathrm{mg} / \mathrm{kg}$ diazepam as premedication one hour before subarachnoid injection with sip of water.

Systemic blood pressure, heart rate, ECG and $\mathrm{SpO} 2$ were monitored in operation theatre. Spinal anaesthesia was given and time of spinal anaesthesia delivered was recorded.

Electrocardiogram, blood pressure and heart rate were monitored by the automated oscillographic method and were recorded every 5 minutes till the end of surgery. Hypotension was considered as a $20 \%$ decrease in baseline systolic BP or $\mathrm{BP}<80 \mathrm{mmHg}$ and was treated with mephentermine $6 \mathrm{mg}$ at incremental dose. Bradycardia was considered as heart rate $<50 /$ min, which was treated with atropine $0.3 \mathrm{mg}$ with incremental doses. Side effects like nausea, vomiting, shivering were managed with ondansetrone $8 \mathrm{mg}$ intravenously. The time interval between delivery of bupivacaine and patient received first dose of pethidine as analgesic was recorded.

\section{RESULTS}

A total number of sixty four patients were included in this study and were randomized to clonidine and diazepam premedication groups. Four patients were excluded, (one case converted to general anaesthesia due to inadequate level of block, two cases received opioid intraoperatively due to complaining of pain and fourth case excluded as the plan of surgery was changed). Therefore data of sixty patients was analyzed in this study.

\section{Table-1 Characteristics of the patient}

$\begin{array}{llll} & \text { Clonidine } & \text { Diazepam } & \text { p value } \\ \text { Mean + SD Age }(\text { Yrs }) & 39.93+11.47 & 37.70+12.72 & >0.05(\mathrm{NS}) \\ \text { Mean + SD Weight }(\mathrm{Kg}) & 56.10+5.79 & 59.00+6.63 & >0.05(\mathrm{NS}) \\ \text { Mean + SD Baseline SBP }(\mathrm{mmHg}) & 113.56+10.08 & 110.93+12.28 & >0.05(\mathrm{NS}) \\ \text { Mean + SD Baseline DBP }(\mathrm{mmHg}) & 75.03+8.16 & 73.13+10.42 & >0.05(\mathrm{NS}) \\ \text { Mean + SD baseline HR (Per minute) } & 81.16+8.51 & 83.53+10.04 & >0.05(\mathrm{NS})\end{array}$

Table-2 Distribution of subject according to ASA physical status.

\begin{tabular}{llllll} 
& & \multicolumn{5}{c}{ ASA Physical Status } \\
Group & Patient & ASA 1 & ASA 2 & Total & p value \\
Clonidine & Number & 24 & 6 & 30 & \\
& Percentage & $40.0 \%$ & $10.0 \%$ & $50.0 \%$ & \\
diazepam & Number & 27 & 3 & 30 & 0.4716 \\
& Percentage & $45.0 \%$ & $5.0 \%$ & $50.0 \%$ & \\
Total & Number & 51 & 9 & 60 & \\
& Percentage & $85.0 \%$ & $15.0 \%$ & $100.0 \%$ &
\end{tabular}

There were higher number of ASA 2 status patients in clonidine premedication Group 6 than diazepam 3 but the difference was not statistically significant. $p$ value $0.4716(>0.05)$. 
Table-3 Haemodynamic parameters (Hypotension)

\begin{tabular}{|c|c|c|c|c|c|}
\hline \multirow[t]{2}{*}{ Group } & \multirow[t]{2}{*}{ Patient } & \multicolumn{3}{|c|}{ Hypotension } & \multirow[b]{2}{*}{$p$ value } \\
\hline & & Yes & No & Total & \\
\hline \multirow[t]{2}{*}{ Clonidine } & Number & 9 & 21 & 30 & \\
\hline & Percentage & $15.0 \%$ & $35.0 \%$ & $50.0 \%$ & \\
\hline \multirow{2}{*}{$\begin{array}{r}\text { Diazepam } \\
\mathrm{P}\end{array}$} & Number & 10 & 20 & 30 & 0.781 \\
\hline & tage & $16.7 \%$ & $33.3 \%$ & $50.0 \%$ & \\
\hline \multirow[t]{2}{*}{ Total } & & 19 & 41 & 60 & \\
\hline & tage & $31.7 \%$ & $68.3 \%$ & $100.0 \%$ & \\
\hline
\end{tabular}

Hypotension was occurred in $9(15 \%)$ in clonidine group and $10(16.7 \%)$ in diazepam group, There is no significant difference between two groups. Chi square value is 0.077 and $p$ value $0.781(>0.05)$.

Fig.1 Distribution of hypotension during surgery

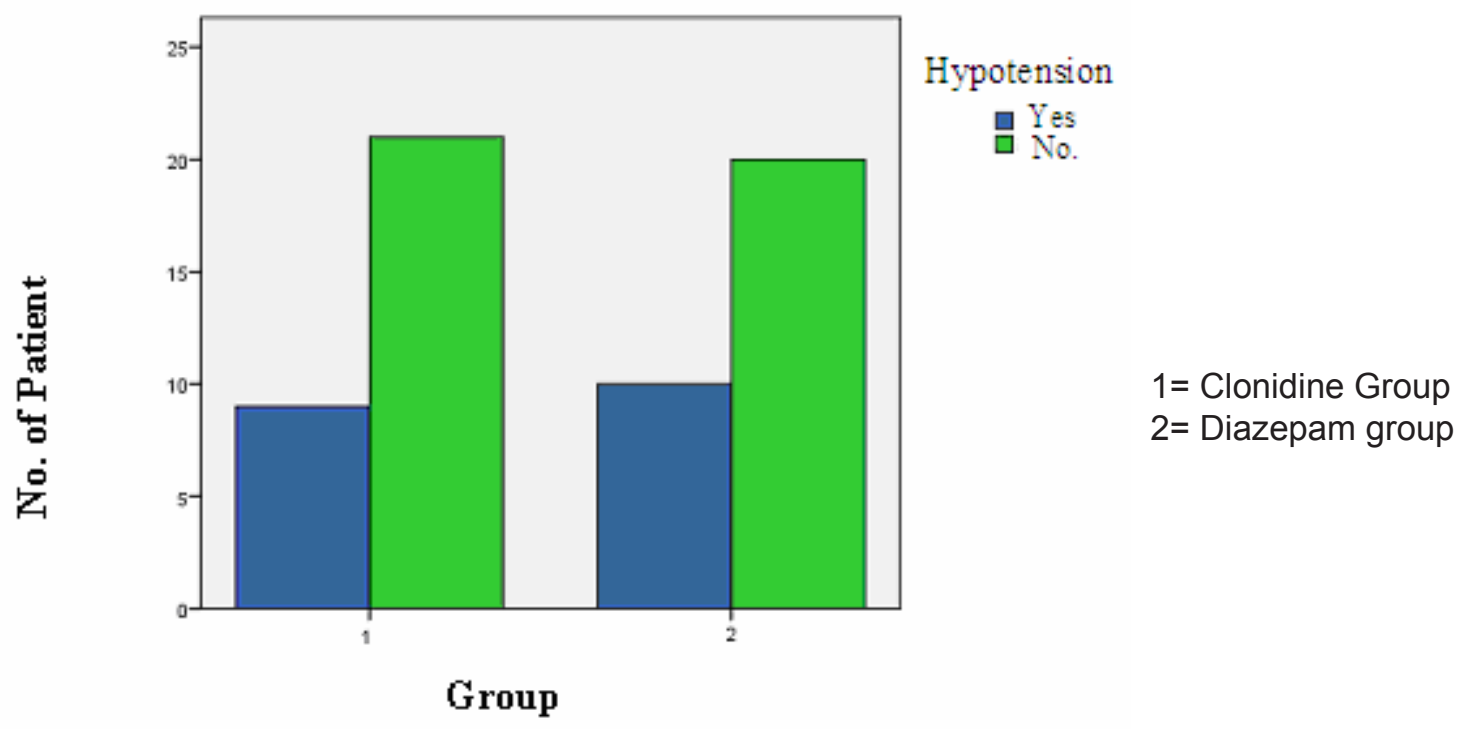

Table-4 Haemodynamic parameters (Bradycardia).

\begin{tabular}{llllll} 
& & \multicolumn{4}{l}{ Bradycardia $(\mathbf{H R}<50)$} \\
Group & Patient & Yes & No & Total & p value \\
Clonidine & Number & 3 & 27 & 30 & \\
& Patient & $5.0 \%$ & $45.0 \%$ & $50.0 \%$ & \\
Diazepam & Number & 6 & 24 & 30 & 0.4708 \\
& Percentage & $10.0 \%$ & $40.0 \%$ & $50.0 \%$ & \\
Total & Number & 9 & 51 & 60 & \\
& Percentage & $15.0 \%$ & $85.0 \%$ & $100.0 \%$ &
\end{tabular}

During surgery, bradycardia was noted in $6(10 \%)$ vs. $3(5 \%)$ patient in diazepam and clonidine group respectively. There is no significant difference between two groups. Chi square value is 0.52 and $P$ value $0.4708(>0.05)$.

Hypertension and tachycardia were not noted in all 60 cases during surgery. 
Table - 5 Side effects.

\begin{tabular}{|c|c|c|c|c|c|c|c|c|}
\hline \multirow{3}{*}{ Group } & \multirow{3}{*}{ Patients } & \multirow{3}{*}{ Nausea } & \multicolumn{6}{|c|}{ Side effects } \\
\hline & & & Shivering & *No Side & & $>1$ side & & \\
\hline & & & & effects & Restless & effect & Total & $p$ value \\
\hline \multirow[t]{2}{*}{ Clonidine } & Number & 5 & 2 & 20 & 3 & 0 & 30 & \\
\hline & Percentage & $8.3 \%$ & $3.3 \%$ & $33.3 \%$ & $5.0 \%$ & $.0 \%$ & $50.0 \%$ & \\
\hline \multirow[t]{2}{*}{ Diazepam } & Number & 1 & 3 & 18 & 7 & 1 & 30 & 0.23 \\
\hline & Percentage & $1.7 \%$ & $5.0 \%$ & $30.0 \%$ & $11.7 \%$ & $1.7 \%$ & $50.0 \%$ & \\
\hline \multirow[t]{2}{*}{ Total } & Number & 6 & 5 & 38 & 10 & 1 & 60 & \\
\hline & Percentage & $10.0 \%$ & $8.3 \%$ & $63.3 \%$ & $16.7 \%$ & $1.7 \%$ & $100.0 \%$ & \\
\hline
\end{tabular}

${ }^{*}$ No side effects other than haemodynamic.

Nausea, shivering, restlessness were other side effects seen during surgery in both clonidine and diazepam group(33.33\% vs. $36.66 \%)$, Although few more cases of nausea (1 vs. 5 ) with clonidine and few more cases of restless ( 3 vs. 7) were noted with diazepam, there is no significant difference between two groups. Chi square value is 5.57 and $p$ value $0.2326(>0.05)$.

Table-6 Time of first dose analgesia.

$\begin{array}{lccc}\text { Group } & \text { Mean(+SD) time of first dose of analgesia(min.) } & \text { t-test } & \text { p value } \\ \text { Clonidine } & 261.90+33.03 & 15.07 & <0.001 \\ \text { Diazepam } & 135.60+31.86 & & \end{array}$

The mean+/- SD time of first dose analgesia was $(261+33.03)$ min in clonidine premedication group which was statistically significantly prolonged than diazepam premedication group $(135.60+31.86)$ minutes. $p$ value $<0.001$.

\section{DISCUSSION}

Intrathecal clonidine has been shown to be effective in opioid-tolerant patients and has been used extensively in the treatment of chronic and intractable pain, neuropathic pain, and cancer pain. ${ }^{12}$ Oral administration is both simpler and cheaper than intrathecal administration and is suitable for use as a premedication. Its sedative effects, combined with anxiolysis and a favorable haemodynamic profile at low doses, makes clonidine a good preoperative medication. In fact, the anxiolytic effects of clonidine and benzodiazepines have been demonstrated to be comparable. 9 Clonidine has further advantage of producing sedation and prolongs postoperative analgesic period, decreases total post operative opioids consumption, but the major side effect, i.e. antihypertensive effect, limits its use as premedication agent. ${ }^{13}$

Study showed pressure responses to noradrenaline and phenylephrine are enhanced by clonidine premedication. ${ }^{14}$ In addition, previous studies suggest that clonidine may also affect peripheral sensory nerves as a sole agent or in combination with local anaesthetics. ${ }^{15}$

Clonidine premedication in a dose of $5 \mathrm{mcg} / \mathrm{kg}$ may be particularly well suited for elderly patients. To pursue this approach, sedation, intraocular pressure (IOP), and the hemodynamic profile of two doses of oral clonidine premedication were compared in 60 elderly patients, aged 65-82 year, who underwent elective ophthalmic surgery under local anesthesia. Results suggest that a dose of $150 \mu \mathrm{g}$ of clonidine, given orally 90-120 min preoperatively to elderly patients is as effective as a dose of $300 \mathrm{mcg}$ in decreasing IOP perioperatively, without causing excessive hemodynamic depression and sedation. ${ }^{16}$

Clonidine easily crosses blood-brain barrier and therefore may interact with alpha -adrenergic receptors at spinal and supraspinal sites within the central nervous system. In addition previous studies suggest that clonidine may also affect peripheral sensory nerves as a sole agent 
or in combination with local anaesthetics. ${ }^{17}$ Premedication with $4-5 \mathrm{mcg} / \mathrm{kg}$ oral clonidine was compared with $0.20-0.25 \mathrm{mg} / \mathrm{kg}$ oral diazepam. Duration of sensory blockade by bupivacaine and fentanyl spinal anaesthesia as significantly prolonged in clonidine group. ${ }^{18}$

The analgesic effect of clonidine is mediated by the same central alpha 2 adrenoreceptors that mediated its hypotensive effects.

In our study, premedication with oral clonidine 4 $\mathrm{mcg} / \mathrm{kg}$ was compared with oral diazepam 0.20 $\mathrm{mg} / \mathrm{kg}$ for patients undergoing surgery under spinal anaesthesia with hyperbaric bupivacaine. Intraoperative haemodynamic changes were similar in both groups, but clonidine group had longer postoperative analgesic period. This result is consistent with the study done in 1992, by Ota K, Namiki K, Ujike Y \& Takahashi I. They concluded that sensory analgesia of spinal tetracaine was prolonged by oral clonidine premedication because of its capacity to prolong sensory blockade $\&$ its potent sedating properties. ${ }^{19}$

In our study, duration of sensory block following spinal anaesthesia with $0.5 \%$ hyperbaric bupivacaine was significantly prolonged when the patients were premedicated with oral clonidine. The result is consistent with the findings of study done by Singh H, George YG and Paul FW ${ }^{20}$ in which oral clonidine prolonged the duration of tetracaine's sensory \& motor block.

Some other studies $16-20$ showed patients treated with clonidine before and 24 hours after sur- gery had a larger reduction of anxiety and pain levels after surgery, reduced the heart rate perioperatively and enhanced sleepiness immediately after surgery.

Bradycardia and hypotension are adverse effects of alpha 2-adrenergic agonists. However, these effects prevent tachycardia and hypertension. Risk of cardiac ischemia is reduced by blunting the sympathetic activity on the cardiovascular system after surgical stress and emergence from anesthesia ${ }^{21}$. Thus, clonidine may be an alternative therapy in patients with cardiac risk factors who are undergoing noncardiac surgery. In this study, neither clinically significant hypotension nor use of larger doses of vasopressor drugs was observed. Clonidine decreases opioid use and lowers hormonal response while maintaining stable hemodynamics in patients undergoing CABG .

These results suggest oral clonidine could be a better therapeutic alternative to other preoperative sedatives. Further studies are necessary to compare its effects with other anxiolytics on postoperative outcomes in other cardiac and noncardiac surgeries.

\section{CONCLUSIONS}

Oral clonidine premedication had similar hemodynamic response to diazepam. It is cheaper and has longer postoperative analgesic effect as well as similar sedative effect. Further studies are needed to support its use in coronary artery bypass and other orthopedic, paediatric and general surgeries. 


\section{REFERENCES}

1. Maze M, Tranquilli W. Alpha-2 adrenoceptor agonists: Defining the role in clinical anesthesia. Anesthesiology 1991; 74: 581-605.

2. Dobrydnjov I, Axelsson K, Gupta A, Lundin A, Holmström B, Granath B. Improved analgesia with clonidine when added to local anesthetic during combined spinal-epidural anesthesia for hip arthroplasty: a double-blind, randomized and placebo-controlled study. Acta Anaesthesiol Scand. 2005;49(4):538-45.

3. Dobrydnjov I, Axelsson K, Samarütel J, Holmström B. Postoperat ive pain relief following intrathecal bupivacaine combined with intrathecal or oral clonidine. Acta Anaesthesiol Scand. 2002;46(7):806-14.

4. Watanabe $\mathrm{Y}$, lida $\mathrm{H}$, Tanabe $\mathrm{K}$, Ohata $\mathrm{H}$, Dohi S. Clonidine premedication modifies responses to adrenoceptors antagonists and baroreflex sensitivity. Can J Anaesth 1998; 45: 1084-90.

5. Niemi L. Effects of intrathecal clonidine on duration of bupivacaine spinal anaesthesia, haemodynamics, and postoperative analgesia in patients undergoing knee arthroscopy. Acta Anaesthesiol Scand 1994; 38: 724-8.

6. Nishina K, Mikawa K, Shiga M, Obara H. Clonidine in paediatric anaesthesia. Paediatr Anaesth 1999; 9: 187-202

7. Park J, Forrest J, Kolesar R. Oral clonidine reduces postoperative PCA morphine requirements. Can J Anaesth 1996; 43: 900-6.

8. Tanaka M, Nishikawa T. Oral clonidine premedication does not alter the efficacy of simulated intravenous test dose containing low dose epinephrine in awake volunteers. Anaesthesiology 1997; 87: 285-8

9. N. Toshniwal, A. Halbe \& H. Iyyer . Study of comparative effects of oral clonidine vs oral diazepam pre-medication on the extent and duration of sensory blockade in patients undergoing vaginal hysterectomy under spinal anaesthesia. The Internet Journal of Anesthesiology 2009 ; 19: 2

10. Kock M, Gautier P, Fanard L. Intrathecal ropivacaine and clonidine for ambulatory knee arthroscopy: a dose-response study. Anesthesiology 2001; 94: 574-8.

11. Howie MB, Hiestand DC, Jopling MW, Romanelli VA, Kelly WB, McSweeney TD, Effect of oral clonidine premedication on anesthetic requirement, hormonal response, hemodynamics, and recovery in coronary artery bypass graft surgery patients. J Clin Anesth. $1996 ; 8(4): 263-72$.

12. Filos KS, Goudas LC, Patroni O, Polyzou V. Hemodynamic and analgesic profile after intrathecal clonidine in humans. A dose-response study. Anesthesiology. 1994;81(3);:591-601

13. Ota K, Akiyoshi N,Yoshihito U, Ikuko T, Prolongation of tetracaine spinal anesthesia by oral clonidine. Anesth Analg 1992;75;262-4

14. Singh H, Geoge Y, Gaines W, White P. Effects of oral clonidine and intrathecal clonidine on tetracaine spinal block. Anesth Analg 1994;79;1113-6 52.

15. Bonnet F, Buisson VB, Francois Y. Effects of oral and subarachnoid clonidine on spinal anesthesia with bupivacaine. Reg Anesth 1990; 15: 211-4.

16. Maruyama K, Hongo T. Oral clonidine premedication exacerbates hypotension following tourniquet deflation by inhibiting noradrenaline release. J Nippon Med Sch 2004; 71(1): 44-50.

17. Inomata S, Yaguchi Y, Kihara S, Toyooka H. The effects of oral clonidine premedication on MAC and MAC for tracheal intubation (MAC-EI) of sevoflurane in children. Anaesthesiology 1998; 89: A1258

18. Tanaka M, Nishikawa T. Effects of clonidine premedication on the pressor response to alpha adrenergic agonists. $\mathrm{Br} \mathrm{J}$ Anaesth 1995; 75: 593-97

19. 19. Harron DW, Riddell JG, Shanks RG. Effects of azepexole and clonidine on baroreceptor mediate reflex bradycardia and physiological tremor in man. $\mathrm{Br} \mathrm{J}$ Clin Pharmacol 1985;20:431-36.

20. 20. Mayson KV, Gofton EA, Chambers KG Premedication with low dose oral clonidine does not enhance postoperative analgesia of intrathecal morphine. Can J Anaesth. 2000;47(8):752-7.

21. Abbas O, Mojgan J, Alieh Z, Maryam J, Ashrafi AT. Analgesic and antisympathetic effects of clonidine in burn patients, a randomized, double-blind, placebo-controlled clinical trial. Br J Anaesth 2007;75 593-59767. 